Viti iXII ${ }^{\text {të }}$ iBotimit, Nr.1-2,

Dhjetor 2020

\title{
NJË VËSHTRIM I PËRGJITHSHËM MBI PËRDORIMIN E E-COMMERCE NË SHQIPËRI
}

\author{
Besjana Tosuni*, Paola Mbroci** \\ *Departamenti i Inxhinierive, Fakulteti i Shkencave të Aplikuara dhe Ekonomike, \\ Albanian University
}

Adresë kontakti: besjanatosuni@albaniauniversity.edu.al

\section{Përmbledhje}

E-commerce (tregtia elektronike) është një ndryshim paradigmë që ndikon në të dy komponentë; tek tregtarët dhe konsumatorët. E-commerce është më shumë se një mënyrë tjetër për të rritur praktikat ekzistuese të biznesit. Ajo po çon në ndryshim të plotë të mënyrën tradicionale të të bërit biznes. Ky ndryshim i rëndësishëm në modelin e biznesit po dëshmon një rritje të jashtëzakonshme në mbarë globin dhe Shqipëria nuk është një përjashtim. Një depërtim masiv i internetit ka shtuar rritjen e tregtisë elektronike dhe më shumë, veçanërisht bizneset e reja kanë përdorur gjithnjë e më shumë këtë opsion si një model biznesi që diferencon.Hulumtimi i tanishëm është ndërmarrë për të përshkruar skenarin e e-Commerce, për të analizuar tendencat e e-Commerce në Shqipëri, problematikat dhe rekomandimet që japin specialistët në lidhje me të.

Fjalë çelës: e-commerce, avantazhet, impakti, teknologji.

\section{A GENERAL OBSERVATION ON THE USE OF E-COMMERCE IN ALBANIA}

\begin{abstract}
E-commerce is a paradigm shift that affects both components; to traders and consumers. E-commerce is more than just another way to enhance existing business practices. It is leading to a complete change in the traditional way of doing business. This significant change in the business model is witnessing tremendous groëth around the globe and Albania is no exception. Massive internet penetration has added to the growth of e-commerce and more, especially beginners have increasingly used this option as a business model that differentiates.
\end{abstract}


Besjana Tosuni, Paola Mbroci

The current research is undertaken to describe the e-Commerce scenario, to analyze the e-Commerce trends in Albania, the problems and recommendations given by specialists in relation to it.

Keywords: e-commerce, advantages, impact, technology.

\section{Hyrje}

Tregtia është mekanizmi kryesor në mbështetje të aktivitetit ekonomik. Ajo është i gjithë sistemi i një ekonomie, i cili krijon mjedisin për biznesin dhe përfshin sistemet ligjore, ekonomike, politike, sociale, kulturore dhe teknologjike që veprojnë në çdo vend.

Shitja me pakicë është elementi më i rëndësishëm i tregëtisë. Ajo përfaqëson shitjen e produkk teve dhe shërbimeve nga individët ose bizneset tek përdoruesi fundor. Në thelb, ndryshimi në shitjen me pakicë në të kaluarën, është promovuar nga ndërveprimi i konsumatorit, shitësit me pakicë dhe qeverisë. Pas viteve 90', këtyre faktorëve i shtohet edhe roli shumë i rëndësishëm i teknologjisë. Ndryshimet demografike, tendencat socialekonomike, mënyra e jetesës dhe faktorë të tjerë, kanë ndikuar në ndryshimet e shitjes me pakicë. Një nga nxitësit kryesorë të zhvillimit ekonomik, i cili është bërë veçanërisht i ndjeshëm gjatë viteve të fundit është teknologjia. Teknologjia është një proces, të cilin shtetet duhet ta promovojnë në mënyrë aktive dhe të ndërgjegjshme.Në ditët e sotme, kombinimi i shitjeve me pakicë në dyqan me atë online, sjell përfitime të dyanëshme, si për konsumatorin, ashtu edhe për shitësin. Komunikimi i dyanshëm, si në kuptimin fizik, ashtu edhe atë të informacionit, ka mundësuar prezencë në tregje më të gjera gjeografike. Shitësit me pakicë përqafojnë zhvillimet e teknologjisë për ndarjen e të dhënave me furnizuesit dhe komunikojnë me klientët e tyre. Teknologjitë e reja janë aplikuar në të gjithë zinxhirin e furnizimit, për të siguruar që produktet të jenë të dizenjuara e testuara, të prodhuara dhe të shpërndara nëpërmjet kanaleve të furnizimit të shpejtë dhe me një kosto të ulët. Edhe sot, shumë kohë pas shfaqjes së të ashtuquajturit «dot.com» / «Internet Revolution», tregtia elektronike mbetet relativisht e re, duke u zhvilluar dhe ndryshuar vazhdimisht në hapësirën e menaxhimit të biznesit dhe teknologjisë së informacionit. Tregtia elektronike bazuar në TIK, ka një potencial të jashtëzakonshëm për të përmirësuar efikasitetin e tregtisë globale dhe për të integruar vendet në zhvillim në këto zhvillime. Ndërgjegjësimi dhe zbatimi i TIK-ut, duke përfshirë tregtinë elektronike, po bëhet një komponent vital i zhvillimit edhe në vendet në zhvillim. Nga ana tjetër, kjo i mundëson vendeve të zhvilluara që të arrijnë marrëdhënie më efikase tregtare me vendet në zhvillim. Numri i përdoruesve të internetit në botë është në rritje në mënyrë të konsiderueshme dhe kjo ka ndikuar në rritjen e shanseve për e-commerce si në fushën rajonale dhe globale. Megjithatë, përveç numrit vazhdimisht më të lartë të përdoruesve të internetit, ekzistojnë elemente të tjera të shumta që ndikojnë në pranimin dhe përparimin e tregtisë elektronike në vendet në zhvillim. 
NJË VËSHTRIM I PËRGJITHSHËM MBI PËRDORIMIN E E-COMMERCE NË SHQIPËRI

\section{2. Ç’është e-commerce? Përfitimet nga përdorimi i saj.}

E-commerce nënkupton tregtinë elektronike. Kjo do të thotë të merresh me mallra dhe shërbime përmes medias elektronike dhe internetit. E-commerce përfshin kryerjen e një biznesi me ndihmën e internetit dhe duke përdorur teknologjinë e informacionit si Electronic Data Interchange (EDI).

E-Commerce lidhet me një faqe të internetit të shitësit në internet, i cili tregton produkte ose shërbime drejtpërdrejt te klienti nga portali. Portali përdor një karrocë digjitale ose një sistem të shportës digjitale dhe lejon pagesën përmes kartave të kreditit, kartës së debitit ose pagesave EFT (Electronic fund transfer).

Një përkufizim më i plotë është: E-commerce është përdorimi i komunikimeve elektronike dhe teknologjisë së përpunimit të informacionit digjital në transaksionet e biznesit për të krijuar, transformuar dhe ridefinuar marrëdhëniet për krijimin e vlerës në mes të organizatave dhe midis organizatave dhe individëve. Llojet kryesore të tregtisë elektronike janë: biznesi në biznes (B2B); biznes-konsumator (B2C); biznesi në qeveri (B2G); konsumator-konsumator $(\mathrm{C} 2 \mathrm{C})$; dhe tregtisë mobile (m-commerce). Përfitimet që vijnë nga përdorimi i e-commerce janë si më poshtë $[1,2]$ :

\subsection{PËRFITIMI KOMERCIAL I E- COMMERCE}

Përfitimet nga tregtia elektronike përfshijnë shpejtësinë e qasjes, një përzgjedhje më të gjerë të mallrave dhe shërbimeve, si dhe qasjen dhe arritjen ndërkombëtare. Dobësitë e perceptuara përfshijnë shërbimin e konsumatorëve ndonjëherë të kufizuar të cilët nuk janë në gjendje të shohin ose prekin një produkt para blerjes dhe kohën e nevojshme të pritjes për dërgimin e produktit. Për të siguruar sigurinë, privatësinë dhe efektivitetin e tregtisë elektronike, bizneset duhet të vërtetojnë transaksionet e biznesit, të kontrollojnë qasjen në burime të tilla si ëebfaqe për përdoruesit e regjistruar ose të përzgjedhur, të encryptojnë komunikimet dhe të zbatojnë teknologjitë e sigurisë.

\subsection{PËRFITIMET E ORGANIZATAVE}

E-commerce ka shumë përparësi për organizatat, disa prej të cilave janë si më poshtë:

- Zgjeron tregjet në tregjet kombëtare dhe ndërkombëtare,

- Zvogëlon koston e krijimit, përpunimit, shpërndarjes, ruajtjes dhe rikthimit të informacionit të bazuar në letër,

- lejon inventarin e reduktuar duke lehtësuar menaxhimin e zinxhirit të furnizimit të tipit "pull",

- zvogëlon kohën midis shpenzimeve të kapitalit dhe marrjes së produkteve dhe shërbimeve, 
Besjana Tosuni, Paola Mbroci

- mbështet përpjekjet e ri-inxhinierimit të proceseve të biznesit (BPR) [3].

\subsection{PËRFITIM PËR KLIENTËT}

E-Commerce u mundëson klientëve të bëjnë ose kryejnë transaksione të tjera 24 orë në ditë, gjatë gjithë vitit nga pothuajse çdo lokacion, u ofron konsumatorëve më shumë zgjedhje, u ofron klientëve

produkte dhe shërbime më pak të shtrenjta duke i lejuar ata për të blerë në shumë vende dhe për të kryer krahasime të shpejta, mundëson shpërndarjen e shpejtë të produkteve dhe shërbimeve në disa raste, sidomos me produktet e digjitalizuara, konsumatorët mund të marrin informacion të detajuar në sekonda, u lejon klientëve të ndërveprojnë me klientët e tjerë në komunitetet elektronike dhe të shkëmbejnë ide, si dhe të krahasojnë përvojat, gjithashtu tregtia elektronike lehtëson konkurrencën.

\subsection{PËRFITIMET NË SHOQËRI}

Së fundi, e-commerce mund të ketë efekte të mira në shoqëri të cilat mundësojnë më shumë individë të punojnë në shtëpi dhe të bëjnë më pak udhëtime për blerje, duke rezultuar në më pak trafik në rrugë dhe ndotje më të ulët të ajrit, lejon që disa mallra të shiten me çmime më të ulëta që të përfitojnë dhe personat e varfër, u mundësojnë njerëzve në vendet e Botës së Tretë dhe në zonat rurale të gëzojnë produkte dhe shërbime të cilat përndryshe nuk janë në dispozicion të tyre, lehtëson ofrimin e shërbimeve publike me kosto të reduktuar, rrit efektivitetin dhe / ose përmirëson cilësinë.

\section{Gjendja aktuale e e-commerce në shqipëri}

Nga vëzhgimet e realizuara në lidhje me implementimin e e-commerce në Shqipëri u arrit në disa konkluzione:

- Shqipëria është në fazën e rritjes së tregtisë me pakicë. Ajo ka trashëguar një sektor të prapambetur të TP (Tregëtia me pakicë) deri në vitet $1990 \mathrm{ku}$ gjithçka ishte e centralizuar dhe administrohej nga shteti. Punësimi i punonjësve ishte totalisht i centralizuar nga zyra e punës në komitetet ekzekutive të qyteteve. Mes njësive tregtare nuk kishte konkurencë për produktet, cilësinë dhe çmimin e tyre. Pas viteve '90 TP shënoi një rritje sasiore dhe cilësore. Kështu nga rreth 25.000 njësi tregtimi dhe shërbimi në vitin 1992 sot numërohen rreth 45.000 të tilla. Ndërkohë që paraqitja e njësive tregtare dhe shërbimi ndaj klienti nuk ka të krahasuar. Njësitë e vogla tregtare me siperfaqe 20-50 $\mathrm{m}^{2}$ sot janë zëvendësuar me minimarkete, supermarkete dhe hipermarkete.

- Tregtia me pakicë në Shqipëri jep një kontribut të rëndësishëm në PBB dhe në punësim. 
- Kështu nga të dhënat e INSTAT kontributi mesatar i TP në PBB (Prodhimi i Brendshëm Bruto) për periudhën 2008-2013 është rreth 3.5\%. Ndërkohë që për të njëjtën periudhë, fuqia punëtore në industrinë e tregëtisë me pakicë paraqitet me nivel të ulët aftësish profesionale dhe me moshë relativisht të re. Vihet re një prezencë e të punësuarave femra me mesatarisht $36 \%$ në 5 vitet e fundit. Bazuar në të ardhurat gjithsej të kësaj industrie vit pas viti, mund të themi se performance e shitjeve ka ardhur në rritje.

- Elementë të tillë si ndyshimet demografike, përbërja familjre, zvogëlimi i familjeve dhe ndarja e çifteve nga trungu, globalizimi dhe dixhitalizimin e ekonomisë kanë ndikuar në ndryshimet strukturore të industrisë së shitjes me pakicë.

- Shqipëria, ka miratuar dhe po implementon strategjinë kombëtare për Teknologjinë e Informacionit dhe komunikimit. Rezultatet e saj duken në rritjen e shkallës së penetrimit të internetit nga $4.5 \%$ ne fillim te viteve 2000 në $62.7 \%$ ne vitin 2015 . Po ashtu Shiqëria ka një rritje të madhe të përdorimit të telefonisë fikse dhe mobile si dhe të shkallës së përdorimit të internetit nga paisjet mobile në shkallën $82.3 \%$. Ky zhvillim i TIK i ka dhënë mundësinë kompanive tregtare dhe biznesit në përgjithësi që të shtojnë prezencën e tyre në ëeb, përgjithësisht në reklamimin e aktivitetit dhe komunikimin interaktiv me partnerët e tyre. Në shqipëri janë miratuar një sërë ligjesh për mbrojtjen e konsumatorit dhe të biznesit nga sulmet kibernetike.

- Blerjet online e kanë kaluar stadin e të qënit risi në Shqipëri. Pas skepticizmit të shpërthimit të internetit këto vitet e fundit, ne jemi dëshmitarë të një e-revolucioni të vërtetë në marrëdhëniet e tregtisë dhe në një zhvillim të theksuar në mënyrë të vecantë nga tregtia elektronike e cila lidhet me statusin e penetrimit të internetit në Shqipëri, gje që ka mundësuar hapjen e shitjeve të TP. Të dhënat zyrtare tregojnë se konsumatorët shqiptare janë duke bërë blerje në internet, blerje të cilat vijnë në rritje nga viti në vit. Kështu nga të dhënat e Postës Shqiptare në vitin 2015 kanë ardhur rreth 234.000 pako të vogla postare (blerje online) krahasuar me 34.000 të mesatares së pesë viteve të mëparëshme, por sic edhe tregojnë shifrat konsumatori shqiptar përdor internetin për të bërë blerje në dyqanet online jasht Shqipërisë dhe shumë pak aplikojnë blerje në kompanitë shqiptare në internet.

- Nga vëzhgimet e bëra, rezulton se ka një sërë elementësh që ndikojnë në blerjen e produkteve dhe shërbimeve në internet nga konsumatori shqiptar. Arsyet kryesore janë mosgjetja e produkteve apo shërbimeve në tregun shqiptar, çmimet e produkteve/shërbimeve të perceptuara nga klienti si më të lira se tregu lokal, mundësi më të mëdha përzgjedhje për produktin/shërbimin, mundësi më e madhe për të marrë informacion për produktin dhe për ta krahasuar atë me burime të ndryshme, etj. 
Besjana Tosuni, Paola Mbroci

Konsumatori shqiptar e shikon blerjen në internet edhe si mundësi e mire për të kursyer kohën dhe për t'u ndjerë komod në blerje.

Më poshtë po japim dy tabela të një studimi të bërë mbi një kampion prej 1000 personash të rastësishëm në të gjithë Shqipërinë nga agjensitë e huaja në lidhje me arsyet e mosblerjes në internet dhe produkteve dhe shërbimeve më të aksesueshme përmes e-commmerce në vitin 2018 [4]. Secili person ka pasur më shumë se një mundësi zgjedhjeje.

\section{Tabela 1: Të dhëna mbi produktet/shërbimet e blera}

\begin{tabular}{|l|c|c|}
\hline \multicolumn{1}{|c|}{ Produkti/Shërbimi } & $\%$ & Persona \\
\hline Libra & $31,3 \%$ & 264 \\
\hline CV/Video & $2,7 \%$ & 23 \\
\hline Softëere & $11,3 \%$ & 96 \\
\hline Bileta udhëtimi & $56,6 \%$ & 480 \\
\hline Hotel/Rezervime & $47,3 \%$ & 401 \\
\hline Veshje/Aksesorë & $67,2 \%$ & 570 \\
\hline Pajisje elektronike/Aksesorë & $44,9 \%$ & 381 \\
\hline Pajisje shtëpie & $7,0 \%$ & 59 \\
\hline Të tjera & $20,3 \%$ & 172 \\
\hline
\end{tabular}

Tabela 2: Arsyet e mosblerjes në Internet

\begin{tabular}{|l|c|}
\hline Arsyet e mosblerjes në internet & $\%$ \\
\hline Nukjemi familjar me blerjet online & $37,1 \%$ \\
\hline Jemi të pasigurtë me pagesat online & $35,1 \%$ \\
\hline Jemi të pasigurtë për të dhënat personale & $22,7 \%$ \\
\hline Jemi të pasigurtë për cilësinë e produktit & $39,2 \%$ \\
\hline Ju pëlqejnë blerjet tradicionale (në dyqan) & $22,7 \%$ \\
\hline Ka procedura të komplikuara & $10,3 \%$ \\
\hline Nuk e prek produktin & $19,6 \%$ \\
\hline Transport ishtrenjtë & $5,2 \%$ \\
\hline Të tjera & $6,2 \%$ \\
\hline
\end{tabular}

- Lidhur me prezencën e biznesit shqiptar në shitjet në internet, nga intervistat me përfaqësuesit e bankave rezulton se vetëm dy banka e ofrojnë shërbimin e e-commerce në Shqipëri. Ato janë Credins Bank e cila e ka ofruar e para këtë shërbim dhe Reiffaisen Bank. Paranë elektronike e mundësojnë të gjitha bankat e nivelit të dytë, por jo të gjitha e kanë aksesin e hapur që më kartat e debitit të bësh blerje online [5]. 
- Qëndrimi i konsumatorit ndaj modeleve të blerjeve. Sipas tyre në blerjen tradicionale ata kanë mundësi që ta prekin produktin, ta provojnë apo shijojnë, të marrin informacion nga shitësit apo punonjësit e njësisë së shitjes, dhe nëse e pëlqejnë produktin/ shërbimin e paguajnë cash ose me kartë dhe e marrin me vete. Ndërkohë që në blerjen online, kanë mundësi që të kërkojnë për produktin/shërbimin në më shumë se një shitës, të krahasojnë çmimet mes ofruesve të ndryshëm, të gjëënë produkte apo shërbime që nuk i gjejnë në tregun lokal, të mos dalin nga shtëpia për të bërë blerjen dhe pasi bëjnë përzgjedhjen të bëjnë pagesën me kartë dhe të presin lëvrimin e saj.

- Duke u mbështetur tek studimet e fushës dhe tek studimet e rasteve shqiptare nga sektorë të ndryshëm aktivitetetsh biznesi, rezulton se ekziston një potencial jo i vogël në blerjet online nëse bizneset shqiptare do të implementojnë e-commerce. Së pari sepse një pjesë jo e vogël e produkteve të konsumatori shqiptar i blen jashtë tregut lokal mund të gjenden në tregun shqiptar. Kjo për faktin se pothuaj të gjitha produktet që blihen në tregun nderkombëtar janë nëpër njësitë e shitjes në tregun lokal të blera nga bizneset lokale në të njëjtin burim, madje me çmime më të mira për shkak të blerjes me shumicë. Së dyti, konsumatori shqiptar jo gjithmonë ka informacion për produktet jashtë lokaliteteve ku banon, dhe nëse kjo nuk mundësohet me marketing intensiv nga biznesi shqiptar përsëri do të mbetet i panjohur.

1) 123.al. Është i pari site shqiptar që hapi rrugën drejt shitjeve online.I themeluar nga Laidi Ferruni, sipërmarrësi largpamës që edukoi tregun shqiptar mbi blerjet online. 123. al negocion me bizneset në qytetin tuaj, në mënyrë që ju të përfitoni çmimin më të ulët për shërbimin që kërkoni.

2) Tag.al . Një platformë që shërben për promovimin në web të ofertave të bizneseve me ulje të forta të çmimeve. I lidhur fort pas portalit ikub.al duke u renditur në $r$ · sitet më të klikuara në shqipëri, është kthyer në një nga lojtarët kryesore të tregut të e-commerce.

3) Kaymu.al. Një platformë për tregtinë online prezente në më shumë se 40 vende të botës. Futur fuqishëm në tregun shqiptar me një marketing agresiv në median sociale. Kaymu ka si fokus kryesor shitjen e veshjeve dhe aksesorëve, duke thjeshtëzuar blerjen online me cash-on-delivery (pagesë në dorë).

4) Dyqantaxi.com. Të pranishëm në treg që prej vitit 2011 si pjesë e kompanisë NetTrade Albania. Një markë që po tërheq çdo ditë e më shumë blerës. Emri dyqantaxi.com është i lehtë për tu mbajtur mend dhe shpreh qartë misionin e themeluesve.

5) Simjalti.al. Ky dyqan është orientuar kryesisht për shitjen e produkteve për femra, fëmijë dhe bebe. Vjen si rezultat i një bashkëpunimi dypalësh nga një kompani në Shqipëri me një në E-COMMERCE 10 kompanitë shqiptare më të mira në Hong Kong. 
Besjana Tosuni, Paola Mbroci

Eksperienca e dy kompanive, sjell shërbim cilësor online në Shqipëri me çmime të favorshme direkt nga prodhuesi në Azi.

6) Grepi.al. Operon në tregun shqiptar që prej vitit 2013. Një faqe ndryshe që ofron një gamë të gjerë produktesh, duke filluar nga: pajisjet elektronike, tek çarçafët dhe mbulesat, e deri tek librat.

7) Fshf.org. Një ndër federatat më të suksesshme të këtij viti, synon të jetë e tillë edhe në tregun e shitjeve online. Mund të porositni produktet e Kombëtares Shqiptare dhe çdo produkt tjetër nën logon e FSHF-së.

8) Neptun.al. Ka nisur aktivitetin në vitin 1993. 41 Një ndër kompanitë më të mëdha në vend, me një rrjet të gjerë dyqanesh në Tiranë e rrethe. Lider në shitjen e pajisjeve elektro-shtëpiake në tregun online.

9) Globe.al. E mirëpozicionuar në tregun e pajisjeve elektrike, tashmë po forcon pozitat e saj në tregun online. Kompania vepron në fushën e shitjeve me pakicë dhe shumicë duke ofruar markat më të njohura për konsumatorin shqiptar.

10) Ebuy.al. Pjesë e ikub.al. Ofron një shumë- 1lojshmëri produktesh duke plotësuar kërkesat e çdo blerësi online. Ofrojnë një treg të hapur për të gjitha kompanitë që duan të bëhen pjesëmarrëse dhe duan të shesin diçka në këtë platformë. [7]

\section{Konkluzione dhe rekomandime}

Bazuar në gjendjen aktuale të e-commerce në Shqipëri rekomandimet e mëposhtme do të ishin një indicje për studime dhe kërkime të mëtejshme në fushën e tregtisë me pakicë dhe kombinimin e modeleve të saj të shitjes.

- Rekomandim për menaxherët e rrjeteve tregtare të shitjes me pakicë. Kombinimi i shitjeve në njësitë tradicionale me ato online janë një mundësi shumë e mirë për të rritur shitjet e njësive tregtare e për të përmirësuar performancën e biznesit të tyre. Kjo do të thotë që menaxhërët e nivelit të lartë duhet të fillojnë të bëjnë pjesë të strategjive të tyre të biznesit e-commerce. Në strategjitë e tyre të marketingut, një zë të veçantë duhet të zërë prezenca në internet, jo vetëm në formën e broshurave rek1amuese por edhe nëpërmjet komunikimit interaktiv. Implementimi i e-commerce dhe komunikimi marketing mes biznesit dhe konsumatorit për ta reklamuar këtë të fundit mbetet elementi kyç për një kombinim të shitjeve tradicionale me ato në internet [6];

- Rekomandimi për bankat e nivelit të dytë. Gjatë mbledhjes së të dhënave nga bankat rezulton se implementimin e e-commerce e kanë bërë klientë të cilët biznesin e tyre e kanë ideuar vetëm për shitje online. Ndërkohë që interesi nga klientë me biznes egzistues të tregtisë me pakicë pothuaj nuk e ka aplikuar asnjëri. Shumica e bizneseve 


\section{SHKENCAT E APLIKUARA DHE EKONOMIKE}

NJË VËSHTRIM I PËRGJITHSHËM MBI PËRDORIMIN E E-COMMERCE NË SHQIPËRI

- që bëjnë shitje online janë biznese shërbimi të tilla si agjensi udhëtimi, hotele, shërbim taksi, dhe shume pak ato që ofrojnë shitje produktesh, madje pjesa më e madhe e bizneseve që shesin produkte aplikojnë pagesën në dorë pas dorëzimit të produktit. Kjo kërkon një komunikim më të plotë të përfitimeve të biznesit dhe mundësitë e përdorimit të parasë elektronike.

- Rekomandim për institucionet zyrtare. Nga vështirësitë e dala gjatë mbledhjes dhe analizës së të dhënave, punimi do të ishte më i plotë me të dhëna nëse dëpartamenti i tregtisë me pakicë në INSTA apo në institucione të tjera shtetërore të kishte një nëndarje në numër njësish për kategoritë e TP të tilla si njësi shitje markete, supermarkete, hipermarkete, qendra tregtare, etj. Për institucionet shtetërore, dhënia e informacionit është "tabu”. Hapja e institucioneve për informacion për qytetarët, e për më shumë për studiues të fushave të ndryshme do të ndikonte pozitivisht jo vetëm në transparencën e institucionit por edhe në performancën e tij, pasi studimet e fushave të ndryshme kanë si qëllim që punimet e tyre të ndikojnë në përmirësimin së aktivitetit të tyre.

\section{Referenca}

1. Schafer, J. Ben, Joseph A. Konstan, and John Riedl. "E-commerce recommendation applications." Applications of Data Mining to Electronic Commerce. Springer US, 2001. 115-153.

2. Tarun Kanti Bose . "Critical success factors of SME internationalization" Journal of small business strategy vol. $26 \bullet$ no. 2.2016

3. Daniel, Elizabeth, and Hugh Wilson. "Adoption intentions and benefits realized: a study of e-commerce in UK SMEs.” Journal of Small Business and Enterprise Development $9.4: 331-348$.

4. G. Çela, "Implementation of e-commerce in developing countries: impact and itslimitations-Albanian Case study", Academic Journal of Business, Administration, Law and Social SciencesIIPCCL Publishing, Tirana-Albania, 2016.

5. E-commerce in Developing Countries: Opportunities and challenges for small and medium-sizedenterprises - World Trade Organization, 2013, URL: http://www.wto. org/english/res_e/booksp_e/ecom_brochure_e.pdf

6. Abdul Gaffar Khan. (2016). Electronic Commerce: A Study on Benefits and Challenges in an Emerging Economy. Global Journal of Management and Business Research: B Economics and Commerce Volume 16 Issue 1 Version 1.0 Year 2016.

7. 10 kompanitë shqiptare më të mira në e-commerce. Nr. 7 i revistës Business Magazine Albania. https://businessmag.al/10-kompanite-shqiptare-me-te-mira-ne-e-commerce/ 